\title{
Morphological Measurements of the Normal Distal Femur and Proximal Tibia between Han Chinese and Mongolian Chinese in a Healthy Chinese Population
}

\author{
Mediciones Morfológicas del Fémur Distal Normal y la Tibia Proximal \\ entre Chinos Han y Mongoles en una Población China Sana
}

Zhifeng Zhang'; Qida Zhang ${ }^{2}$; Guanghui Zhao ${ }^{3}$; Jian Huang ${ }^{4}$; Zhenxian Chen ${ }^{5}$; Zhongmin Jin ${ }^{2,6,7}$ \& Yusheng Qiu ${ }^{1}$

ZHANG, Z.; ZHANG, Q.; ZHAO, G.; HUANG, J.; CHEN, Z.; JIN, Z. \& QIU, Y. Morphological measurements of the normal distal femur and proximal tibia between Han Chinese and Mongolian Chinese in a healthy Chinese population. Int. J. Morphol. 37(2): 664-670, 2019.

SUMMARY: This study aims to compare the knee morphological difference between Han and Mongolian Chinese in China. This will improve the knee prostheses design. A total of 37 natural knees of Han Chinese (13 males, 9 females) and Mongolian Chinese (8 males, 7 females) were measured used Mimics medical imaging program, and the parameters included fML (the femoral mediolateral length), fLAP (the femoral lateral condyle anteroposterior length), fMAP (the femoral medial condyle anteroposteriorlength), tML (The tibial mediolateral length ), tLAP (The tibial lateral anteroposteriorlength) and tMAP (the tibial medial anteroposterior length), The aspect ratio (defined as fML/fAP and tML/tAP;). The sizes of femur and tibia of the males were larger than those of the female for Han Chinese (fML, fLAP and fMAP) mean \pm standard deviation: $84.57 \pm 4.70$ vs.76.52 $\pm 3.56,65.75 \pm 2.70$ vs. $60.53 \pm 3.81$ and $67.10 \pm$ 3.67vs. $62.12 \pm 3.55$; tML, tLAP and tMAP: $74.68 \pm 4.27$ vs. $65.82 \pm 3.51,36.13 \pm 2.96$ vs. $31.12 \pm 2.91$ and $44.54 \pm 3.02$ vs. $40.11 \pm$ 3.80 and Mongolian Chinese (fML, fLAP and fMAP) : $88.20 \pm 4.57$ vs. $77.92 \pm 2.97,68.82 \pm 4.22$ vs. $61.31 \pm 1.92$ and $69.81 \pm 3.53$ vs. $62.13 \pm 1.63$; tML, tLAP and tMAP: $78.00 \pm 3.80$ vs. $66.71 \pm 3.52,40.17 \pm 3.09$ vs. $32.91 \pm 1.68$ and $48.65 \pm 3.00$ vs. $41.97 \pm 2.48)$. The aspect ratio of the knee in Mongolian Chinese was smaller than those of Han Chinese (fML/fAP:1.28 \pm 0.04 vs. $1.29 \pm 0.03$ for males; $1.27 \pm 0.04$ vs.1.27 \pm 0.05 ; tML/tAP: $1.60 \pm 0.04$ vs. $1.68 \pm 0.10$ for the males, $1.59 \pm 0.13$ vs. $1.65 \pm 0.10$ for the females). The effects of nationality and sex on the size and shape of knee were significant $(\mathrm{p}<0.05)$. The results suggest that an anatomic matched knee prosthesis should be taken into account different nationalities even in the same race.

KEY WORDS: Ethnic Groups; Knee; Anatomy.

\section{INTRODUCTION}

In total knee replacement (TKR) design, a proper coverage of bone surface is essential for good clinical results and long-term survivorship of prostheses. Many studies using the finite element analysis have demonstrated that a good match between prostheses and bone surface can even minimize the wear of the bearing surfaces (Liau et al., 2002), improve stress distribution (Villa et al., 2004), and prolong the service time of prosthesis (Figgie et al., 1989). On the contrary, any mismatch between prosthesis and bone surface or malposition in the form of overhang or under sizing of the prosthesis may result in a number of severe complications. For the tibia prosthesis, overhang may result in the residual pain (Bonnin et al., 2016). For the distal femur, the case of under sizing may cause prosthesis sinking, potentially leading to revision (Stulberg et al., 1995).

Many studies have suggested that Asian patients may benefit from a smaller knee prosthesis than the Caucasians patients (Vaidya et al., 2000; Mahfouz et al., 2012). A number of studies have also proven that the prostheses designed for

\footnotetext{
${ }^{1}$ Department of Orthopaedics, The First Affiliated Hospital, Xi' an Jiaotong University, 710061, Xi'an, Shaanxi.

${ }^{2}$ State Key Laboratory for Manufacturing System Engineering, School of Mechanical Engineering, Xi'an Jiaotong University, 710054, Xi'an, Shaanxi, China.

${ }^{3}$ Hong-Hui Hospital, Xi'an Jiaotong University College of Medicine, Xi'an, 710054, China.

${ }^{4}$ Department of Joint Surgery, the Second Affiliated Hospital of Inner Mongolia Medical University, 010030 Hohhot, Inner Mongolia, China.

${ }^{5}$ Key Laboratory of Road Construction Technology and Equipment of MOE, Chang' an University, 710064, Xi' an, Shaanxi, China.

${ }^{6}$ Tribology Research Institute, School of Mechanical Engineering, Southwest Jiaotong University, 610031 Chengdu, Sichuan, China.

${ }^{7}$ Institute of Medical and Biological Engineering, School of Mechanical Engineering, University of Leeds, Leeds, LS2 9JT, UK.
} 
European Caucasians are not appropriate for Asian ethnicity (Chaichankul et al., 2011; Sun et al., 2014). The main reason has been identified by the knee morphological differences between Chinese population and Western population (Cheng et al., 2009). To our knowledge, the available knee prostheses designed for Caucasians may not match the Chinese patients, especially in Mongolian Chinese. To our knowledge, many studies have focused on Han Chinese while few studies have focused on the natural knee anatomy in the Mongolian population. The aim of this study is to investigate the effects of nationality and sex on the size and shape of natural knees between Han and Mongolian Chinese of China. The work conducted in this study may provide better guidance for the design and selection of knee prostheses.

\section{MATERIAL AND METHOD}

All subjects were recruited at The Second Affiliated Hospital of Inner Mongolian Medical University, after achieving informed consent from the subjects. A total of 37 healthy natural knees, including Han Chinese 22 cases (13 males, 9 females) and Mongolian Chinese 15 ( 8 males, 7 females), were selected in this study. The range of age was 23-45 years, the average age was 36.0 7 7.2 years. All knees were healthy without any injuries or osteoarthritis, in terms of clinical examination and examination of computer tomographic (CT) images. For all subjects, a multi-slice helical CT scanner (120 kV, 80mA; Light Speed 16; GE, America) was used for scanning. The subject was required in a supine position with his or her lower limbs in a relaxed and neutral rotation. The scanning procedure was performed to acquire $0.625 \mathrm{~mm} \mathrm{CT}$ slices (resolution, $512 \times 512$ pixels) with a field of view of $200 \times 200 \mathrm{~mm}$ around knee joint. The scanning images were exported and saved in DICOM format. All digital three-dimensional (3D) reconstruction of knee was performed using the Mimics medical imaging program (version 16.0; Materialise, Leuven, Belgium). Then threedimensional models were imported to Geomagic studio (version 12.0; Geomagic, USA) for surface reconstruction. At last, morphological measurements were performed in Geomagic studio (version 12.0; Geomagic, USA).

The distal femoral morphology and the proximal tibia morphology were measured with a method reported by Kwak et al. (2007) as shown in Figure 1. The femoral mediolateral length (fML) was referenced by the femoral epicondyle axis, defined as the most salient point between the medial and lateral attachment on the femoral condyle. The femoral medial condyle anteroposterior length (fMAP) was defined as the distance from the most anterior point on the femur medial condyle to the posterior condylar line. The femoral lateral condyle anteroposterior length (fLAP) was taken as the distance from the most anterior point on the femur lateral condyle. The tibial mediolateral length (tML) was the maximum length between medial and lateral tibia plateau, parallel to the axis of the femoral condyle. The tibial lateral anteroposterior length (tLAP) was the length from the anterior lateral tibia plateau to the posterior plateau. The tibial medial anteroposterior length (tMAP) was the length from the anterior medial tibia plateau to the posterior plateau. The femoral aspect ratio (fML/fAP) and tibial aspect ratio (tML/tAP) were considered in our study to interpreting the results of knee shape. All measurements were recorded in millimeters.

The statistical analysis was performed in SPSS software 22.0 (SPSS, Chicago, IL). All measured lengths were summarized as the mean and standard deviation. Comparative statistical analyses between genders and nationalities were made using the independent sample $t$ test, in analyzing the morphometric data, scatter plots along with a best-fit line were represented.

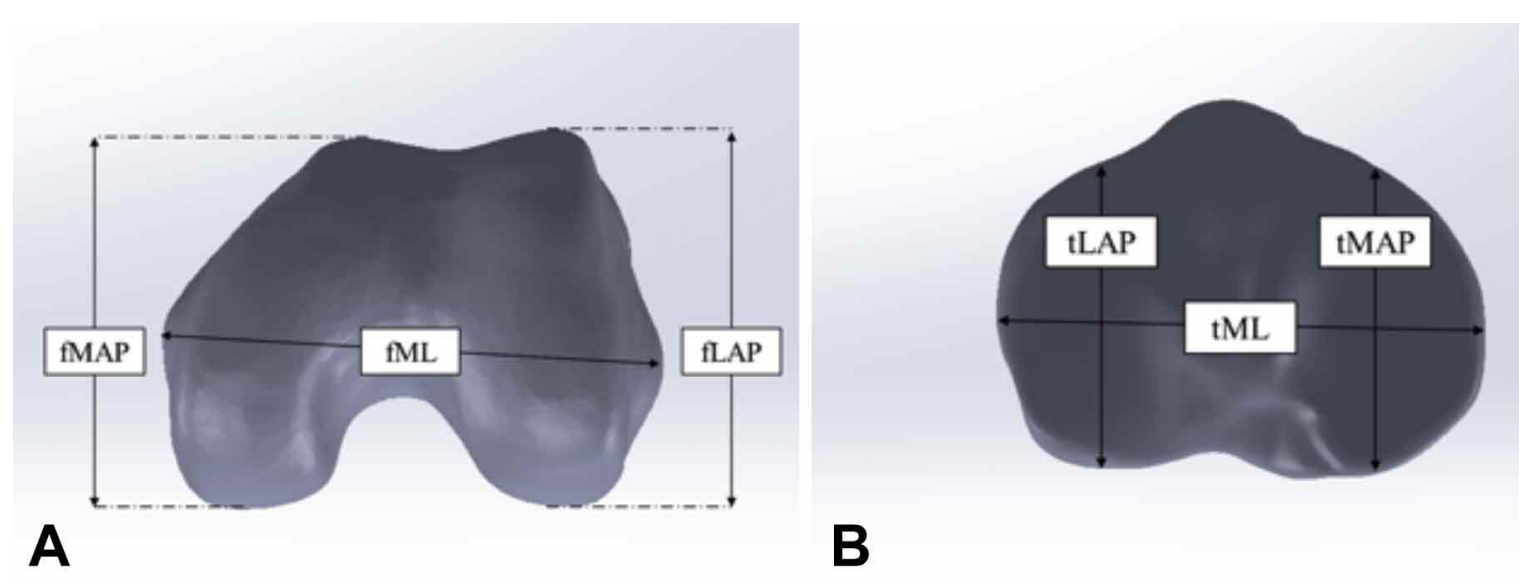

Fig. 1 the measurement of knee distal femoral (A) and proximal tibia (B). 


\section{RESULTS AND DISCUSSION}

The measurement results for femur are presented in Table I. It was observed that all measurements (fML, fMAP and fLAP) of femur had larger size in male than in female both in Mongolian Chinese and Han Chinese $(\mathrm{P}<0.05)$. Mongolian Chinese males had a larger femur (fML, fMAP and fLAP) than Han Chinese males $(\mathrm{p}<0.05)$.

It was observed that all measurements (tML, tMAP and tLAP) of tibia had larger size in male than those in female no matter in Mongolian Chinese or in Han Chinese $(\mathrm{P}<0.05)$ (Table II). Mongolian Chinese males had a larger tibia (tML, tMAP and tLAP) than Han Chinese males $(\mathrm{P}<0.05)$. Though Mongolian Chinese females had a larger tibia (tML, tMAP and tLAP) than those in Han Chinese females ( $\mathrm{P}>0.05)$, there was no statistical difference. The statistical differences in tibia shape between Han Chinese male and Mongolian Chinese male was significant $(\mathrm{P}<0.05)$. Figure 2 shows the difference from nationality and gender of distal femur between the Han Chinese and Mongolian Chinese. The fML was significantly and positively correlated with the fMAP (Fig. 2A) while the fML/fMAP was significantly and negatively correlated with the fMAP (Fig. 2B). For the same fMAP values along the regression curves (Fig. 2A), both Mongolian Chinese males and Han Chinese males had a larger fML than those in the females and showed significant differences. Mongolian Chinese females and Han Chinese

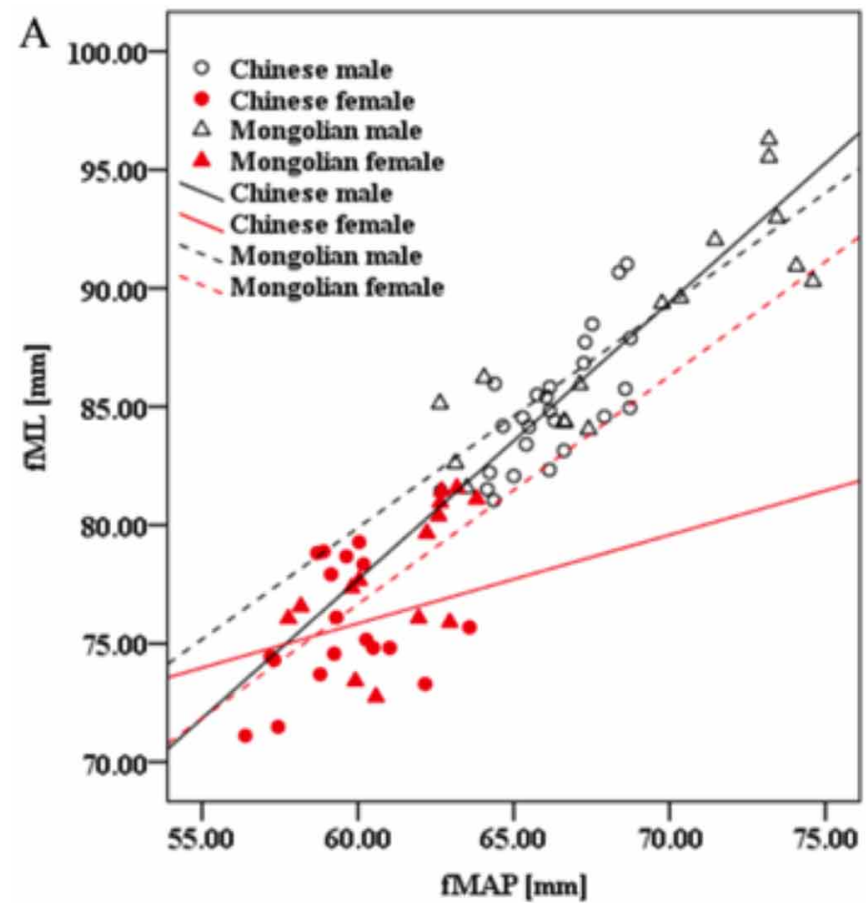

females showed no significant differences in fML, fMAP and fLAP although the values in Mongolian Chinese females were larger than those in Han Chinese females. On the other hand, both Mongolian Chinese and Han Chinese males had larger aspect ratio (fML/fAP) than those in females for the same fMAP values; sex showed significant differences in aspect ratio (fML/fAP) for both Han and Mongolian Chinese. Nationality showed significant differences in fML/fAP ratios in males.

Figure 3 shows the difference from nationality and sex of proximal tibia between the Han Chinese and Mongolian Chinese. The tML was significantly and positively correlated with the tMAP (Fig. 3A) while the aspect ratio (tML/tMAP) was significantly and negatively correlated with the Tmap (Fig. 3B). Both Mongolian Chinese males and Han Chinese males had larger aspect ratios (tML/tAP) than those in the females for the same tMAP values (Fig. 3B). Gender showed significant differences in aspect ratio (tML/tMAP) no matter in Han Chinese or Mongolian Chinese. Nationality showed significantly differences in aspect ratio (tML/tMAP) only in males.

The tMAP was significantly and positively correlated with the fML, the tMAP was increased along with an increasing in the fML (Fig. 4A). The aspect ratio of tibia was significantly and negatively correlated with the fML, and the tMAP was increased along with an increasing in the fML (Fig. 4B).

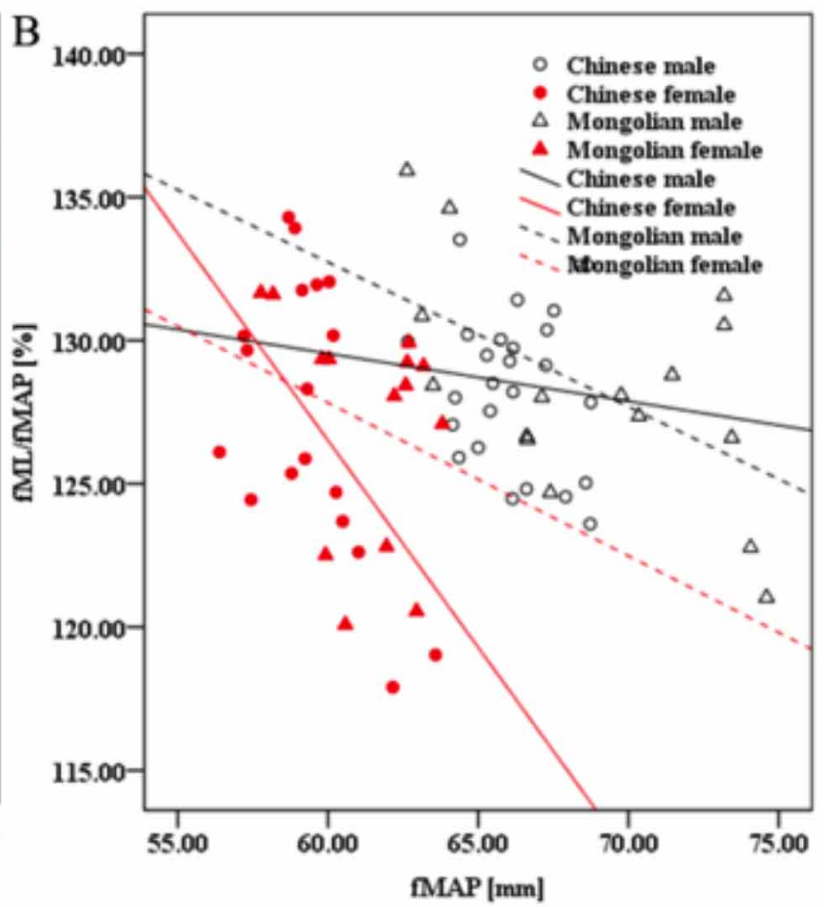

Fig. 2. Difference from nationality and sex of distal femur between the Han Chinese and Mongolian Chinese. 

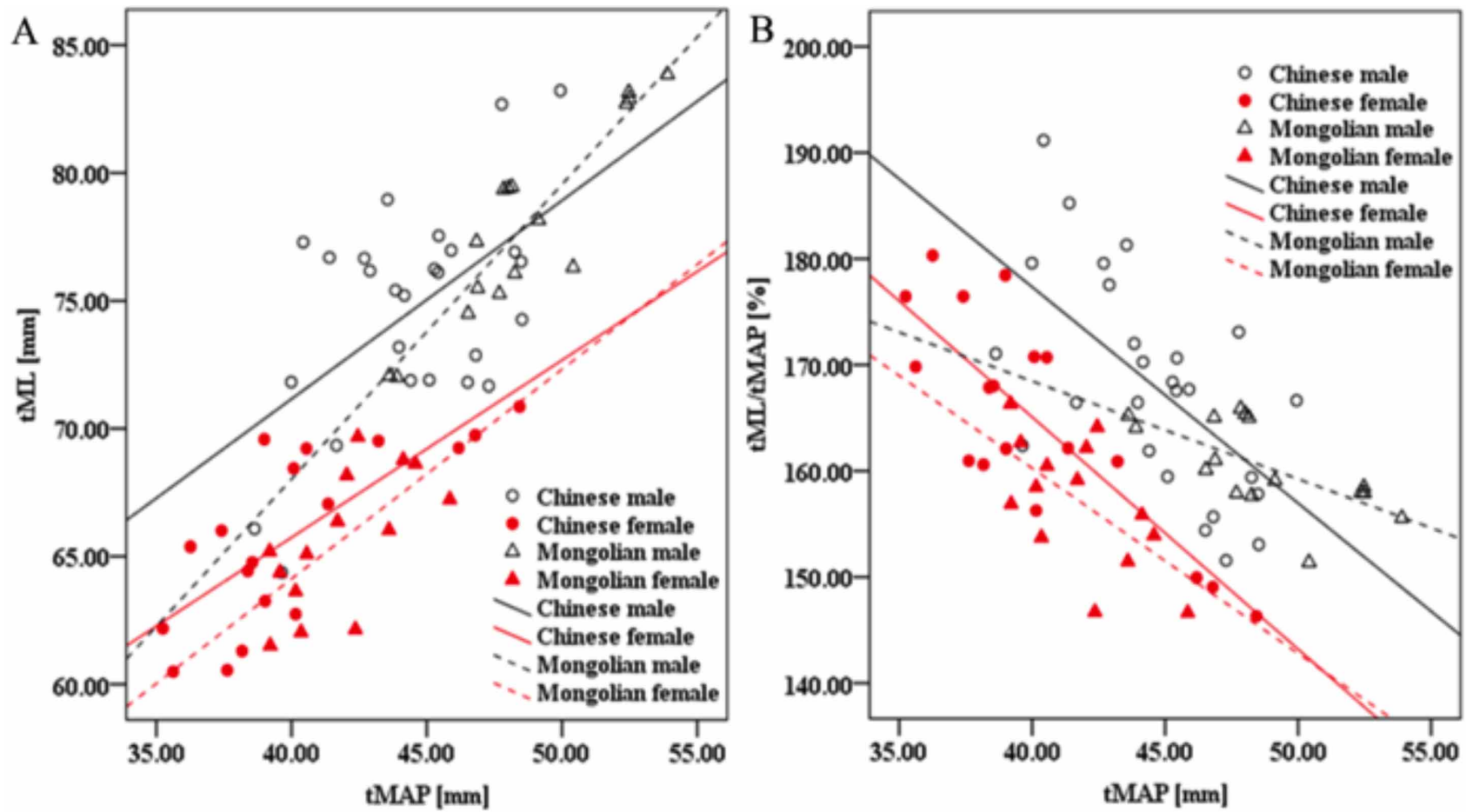

Fig. 3. Difference from nationality and sex of proximal tibia between the Han Chinese and Mongolian Chinese and sex effects on Han Chinese males and females, Mongolian Chinese males and females.
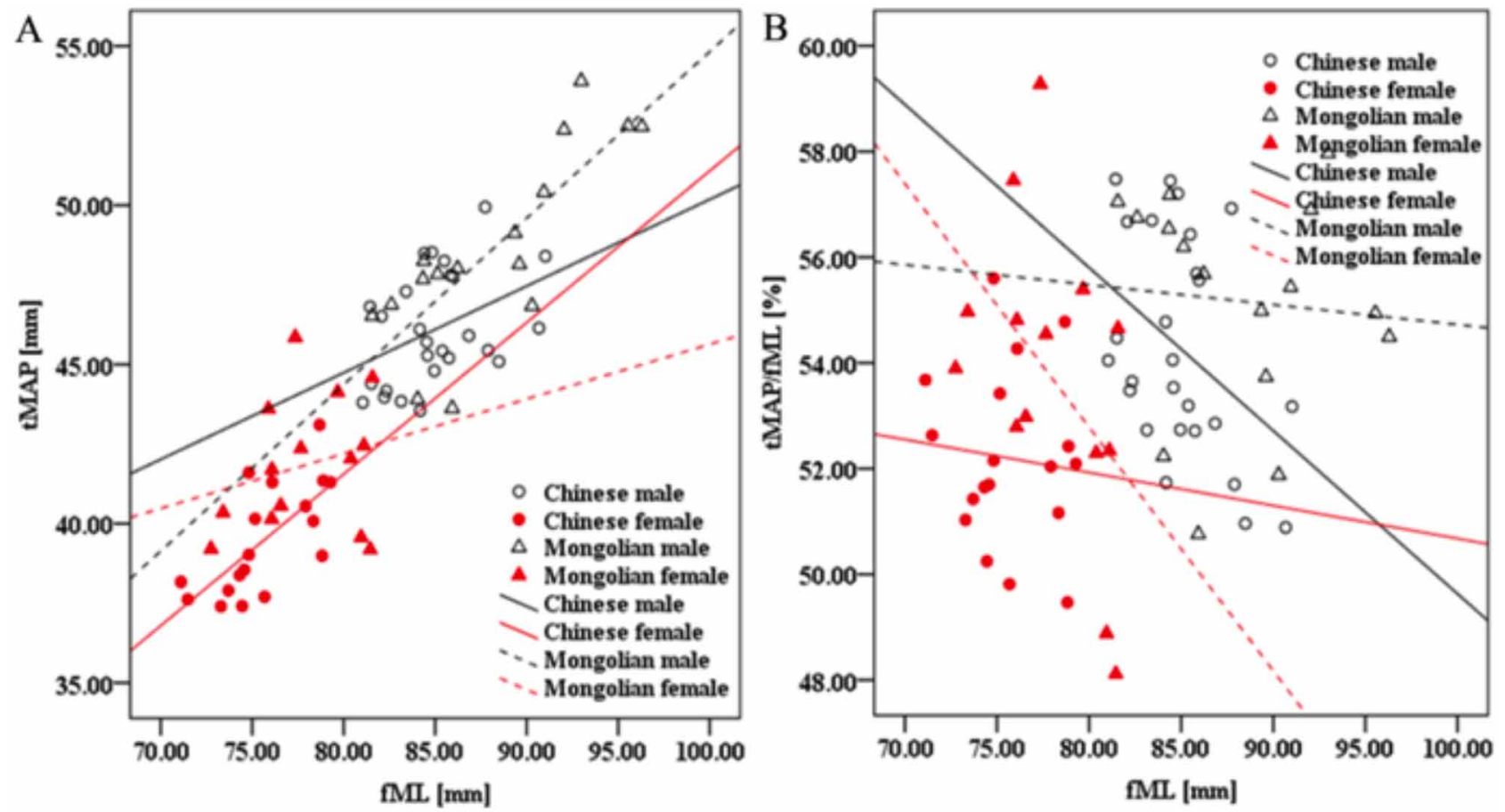

Fig. 4. The morphological relationship between the tibia and femur in Han Chinese and Mongolian Chinese

The morphological character of the distal femur and proximal tibia is different among varius races, and was proved in many studies. But the difference of the distal femur and proximal tibia between divers nationalities still unknown 
ZHANG, Z.; ZHANG, Q.; ZHAO, G.; HUANG, J.; CHEN, Z.; JIN, Z. \& QIU, Y. Morphological measurements of the normal distal femur and proximal tibia between Han Chinese and Mongolian Chinese in a healthy Chinese population. Int. J. Morphol. 37(2): 664-670, 2019.

Table I. Average values of the femur morphology measurement (mm).

\begin{tabular}{lcccc}
\hline Measurements & Mongolian male & Mongolian female & Chinese male & Chinese female \\
\hline fML & $88.20 \pm 4.57$ & $77.92 \pm 2.97$ & $84.57 \pm 4.70$ & $76.52 \pm 3.56$ \\
fLAP & $68.82 \pm 4.22$ & $61.31 \pm 1.92$ & $65.75 \pm 2.70$ & $60.53 \pm 3.81$ \\
fMAP & $69.81 \pm 3.53$ & $62.13 \pm 1.63$ & $67.10 \pm 3.67$ & $62.12 \pm 3.55$ \\
A spect ratio (fML/fAP) & $1.28 \pm 0.04$ & $1.27 \pm 0.04$ & $1.29 \pm 0.03$ & $1.27 \pm 0.05$ \\
\hline
\end{tabular}

Table II. Average values of the tibia morphology measurement (mm).

\begin{tabular}{lcccc}
\hline Measurements & Mongolian male & Mongolian female & Chinese male & Chinese female \\
\hline tML & $78.00 \pm 3.80$ & $66.71 \pm 3.52$ & $74.68 \pm 4.27$ & $65.82 \pm 3.51$ \\
tLAP & $40.17 \pm 3.09$ & $32.91 \pm 1.68$ & $36.13 \pm 2.96$ & $31.12 \pm 2.91$ \\
tMAP & $48.65 \pm 3.00$ & $41.97 \pm 2.48$ & $44.54 \pm 3.02$ & $40.11 \pm 3.80$ \\
Aspect ratio(tML/tAP) & $1.60 \pm 0.04$ & $1.59 \pm 0.13$ & $1.68 \pm 0.10$ & $1.65 \pm 0.10$ \\
\hline
\end{tabular}

in the same race for us, and to know the difference of the distal femur and proximal tibia is also the requirement of medical precision and individuation.

Many studies have reported on the size differences of distal femur resulted from the gender for Han Chinese population. Cheng et al. reported the average $\mathrm{fML}$ dimensions based on CT to be $74.4 \pm 2.9 \mathrm{~mm}$ and $66.8 \pm 3.1$ $\mathrm{mm}$ for males and females in northeast region of China , respectively. However, the different Chinese nationalities have been rarely compared. In this study, the sizes of Han and Mongolian Chinese knees were measured and compared. The measured fML, fLAP and fMAP of Han Chinese were larger than the previous study (Wang et al., 1992; Cheng et $a l$.), maybe as a result of different definition of measured length of femur and tibia or measured methods. For example, for Cheng et al., the tibial mediolateral (tML) dimension was taken as the longest mediolateral length of the proximal tibial cut surface $6 \mathrm{~mm}$ below the medial aspect of the tibial plateau with a $7^{\circ}$ posterior slope. For Wang et al., the measuements based on the x-rays, so it was not very accurately. And the sizes of femur and tibia of Mongolian Chinese were larger than those of Han Chinese. The present study showed that the shape of Han Chinese knees was generally wider than Mongolian Chinese knees in the same sex.

In our study, females also had a narrower distal femur than males both in Han Chinese and Mongolian Chinese according to the statistical analysis, and these results were consistent with the previous studies (Mensch \& Amstutz, 1975; Chin et al., 2002; Hitt et al., 2003). Compared with western population, Mongolian Chinese females had a significantly wider average aspect ratio (fML/fAP) than Caucasian females [1.27 \pm 0.04 vs. 1.19 (Lonner et al., 2008) or 0.99 (Thienpont et al., 2016)]. This suggested that not only the TKA prosthesis design should consider the sex factor, but also the nationality differences. The morphological differences of femoral between Han Chinese and Mongolian Chinese females $(\mathrm{P}<0.05)$ cannot be accounted by the differences in size alone, but also the shape variation between these two nationalities. The components designed based on Han Chinese knee data may lead to a mediolateral component overhang in Mongolian Chinese for the same gender. An overhanging prosthesis is more likely to cause soft tissue imbalance, and unfavorable patellofemoral stress distribution. It is often needed to downsize the femoral components during TKA operation to avoid this clinical overcome. However, this may also result in an undesirable complication. For example, notching of the anterior cortex can predispose to periprosthetic fractures and over-resection of the posterior femoral condyles resulting in an imbalance between the flexion and extension gaps.

The geometry of tibial plateau is considered as an important factor in TKA design and has a direct impact on the biomechanics of tibiofemoral joint (Hashemi et al., 2008). The tibial plateau parameters were measured and compared in this study. The tMAP had larger values than tLAP, which is similar to the previous reports (Hitt et al.; Kwak et al.). However, the size of proximal tibia is larger than the reported results (Wevers et al., 1994; Hitt et al.; Kwak et al.) of the Asia-Pacific population including Chinese population. In addition, the mean aspect ratio (tML/ tAP) showed the significant difference between male and female in our study (p?0.05), and the shape of tibia in female are narrower and smaller than that in male in the same nationality, which is consistent with previous findings (Kwak et al.; Cheng et al.; Lim et al., 2013; Piriou et al., 2014). Moreover, most current prostheses used in China are designed for Caucasian population with an unchanged aspect ratio. A significant aspect ratio difference between Han Chinese and Mongolian Chinese was found in this study. The measurement results implied that it is necessary to adjust the aspect ratio during components design for achieving a better clinical outcome. 
The morphology of femur and tibia should be considered as a whole in the process of knee prosthesis design. The morphological relationship between the tibia and femur of Han Chinese and Mongolian Chinese was investigated in this study. We found that the tML was positively correlated with the fML and fAP, the trend of which was similar to that reported by Cheng et al. Therefore it is important to consider the morphological factors of tibia and femur as a whole for the prosthesis design.

Some limitations of this study should be discussed. First, the sample number of natural knees in this study was limited, and more samples should be recruited in next step. Second, a direct dimensional comparison with the current available knee prostheses was not performed. Moreover, the three-dimensional knee models were made from CT images, where the effects from the cartilage thickness of the femur and tibia were not considered. Despite these, the present study provides useful and essential knowledge about the femur and tibia of Mongolian Chinese and Han Chinese.

\section{CONCLUSION}

Our study showed that the sizes of femur and tibia of the males were larger than those of the female for both Han and Mongolian Chinese. Furthermore, the sizes of femur and tibia of Mongolian Chinese were larger than those of Han Chinese. The aspect ratios of femur and tibia of Mongolian Chinese were smaller than that of Han Chinese. The effects of nationality and sex on the size and shape of proximal tibia and distal femur were significant $(\mathrm{p}<0.05)$. This study implied that engineer design prothesis should taken into account the differences of nationalities.

ACKNOWLEDGMENTS. The authors gratefully acknowledge the support of the Department of Arthroplasty Surgery, the Second Affiliated Hospital of Inner Mongolia Medical University in Inner Mongolia of China.

ZHANG, Z.; ZHANG, Q.; ZHAO, G.; HUANG, J.; CHEN, Z.; JIN, Z. \& QIU, Y. Mediciones morfológicas del fémur distal normal y la tibia proximal entre chinos Han y Mongoles en una población china sana. Int. J. Morphol., 37(2):664-670, 2019.

RESUMEN: Este estudio tiene como objetivo comparar la diferencia morfológica de rodilla entre los chinos Han y los Mongoles en China. Esto mejorará el diseño de las prótesis de rodilla. Un total de 37 rodillas de chinos Han (13 hombres, 9 mujeres) y Mongoles ( 8 hombres 7 mujeres) se midieron utilizando el programa de imágenes médicas Mimics, y los parámetros incluye- ron fML (la longitud mediolateral femoral), fLAP (la longitud anteroposterior del cóndilo lateral del fémur), fMAP (la longitud anteroposterior del cóndilo medial del fémur), tML (la longitud mediolateral de la tibia), tLAP (la longitud anteroposterior lateral de la tibia) y tMAP (la longitud anteroposterior media de la tibia), la relación de aspecto (definida como fML / fAP y tML / tAP;). Los tamaños de fémur y tibia de los hombres fueron mayores que los de las mujeres para los chinos Han (fML, fLAP y fMAP) [media \pm desviación estándar: $84,57 \pm 4,70$ vs. 76,52 $\pm 3,56,65,75 \pm 2,70$ vs. $60,53 \pm 3,81$ y $67,10 \pm 3,67$ vs. $62,12 \pm 3,55$; tML, tLAP y tMAP: $74,68 \pm 4,27$ vs. $65,82 \pm 3,51,36,13 \pm 2,96$ vs. $31,12 \pm 2,91$ y $44,54 \pm 3,02$ vs. $40,11 \pm 3,80$ y Chino Mongol (fML, fLAP y fMAP): $88,20 \pm 4,57$ vs. $77,92 \pm 2,97,68,82 \pm 4,22$ vs. $61,31 \pm 1,92$ y $69,81 \pm 3,53$ vs. $62,13 \pm 1,63$; tML, tLAP y tMAP: $78,00 \pm 3,80$ vs. $6671 \pm 3,52,40,17 \pm 3,09$ vs. $32,91 \pm 1,68$ y $48,65 \pm 3,00$ vs. $41,97 \pm 2,48]$. La relación de aspecto de la rodilla del Chino Mongol fue menor que la de los chinos Han (fML / fAP: 1,28 $\pm 0,04$

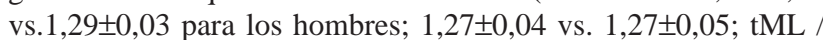
tAP: $1,60 \pm 0,04$ vs. $1,68 \pm 0,10$ para los hombres, $1,59 \pm 0,13$ vs. $1,65 \pm 0,10$ para las mujeres). Los efectos de la nacionalidad y el sexo en el tamaño y la forma de la rodilla fueron significativos ( $\mathrm{p}$ $<0,05)$. Los resultados sugieren que una prótesis anatómica de rodilla emparejada debe tenerse en cuenta en las diferentes nacionalidades, incluso en la misma raza.

PALABRAS CLAVE: Grupos étnicos; Rodilla; Anatomía.

\section{REFERENCES}

Bonnin, M. P.; Saffarini, M.; Shepherd, D.; Bossard, N. \& Dantony, E. Oversizing the tibial component in TKAs: incidence, consequences and risk factors. Knee Surg. Sports Traumatol. Arthrosc., 24(8):2532-40, 2016.

Chaichankul, C.; Tanavalee, A. \& Itiravivong, P. Anthropometric measurements of knee joints in Thai population: correlation to the sizing of current knee prostheses. Knee, 18(1):5-10, 2011.

Cheng, F. B.; Ji, X. F.; Lai, Y.; Feng, J. C.; Zheng, W. X.; Sun, Y. F.; Fu, Y. W. \& Li, Y. Q. Three dimensional morphometry of the knee to design the total knee arthroplasty for Chinese population. Knee, 16(5):341-7, 2009.

Chin, K. R.; Dalury, D. F.; Zurakowski, D. \& Scott, R. D. Intraoperative measurements of male and female distal femurs during primary total knee arthroplasty. J. Knee Surg., 15(4):213-7, 2002.

Figgie, H. E. 3rd.; Goldberg, V. M.; Figgie, M. P.; Inglis, A. E.; Kelly, M. \& Sobel, M. The effect of alignment of the implant on fractures of the patella after condylar total knee arthroplasty. J. Bone Joint Surg. Am., 71(7):10319, 1989.

Hashemi, J.; Chandrashekar, N.; Gill, B.; Beynnon, B. D.; Slauterbeck, J. R.; Schutt, R. C. Jr.; Mansouri, H. \& Dabezies, E. The geometry of the tibial plateau and its influence on the biomechanics of the tibiofemoral joint. J. Bone Joint Surg. Am., 90(12):2724-34, 2008.

Hitt, K.; Shurman, J. R. 2nd; Greene, K.; McCarthy, J.; Moskal, J.; Hoeman, T. \& Mont, M. A. Anthropometric measurements of the human knee: correlation to the sizing of current knee arthroplasty systems. J. Bone Joint Surg. Am., 85-A Suppl. 4:115-22, 2003.

Kwak, D. S.; Surendran, S.; Pengatteeri, Y. H.; Park, S. E.; Choi, K. N.; Gopinathan, P.; Han, S. H. \& Han, C. W. Morphometry of the proximal tibia to design the tibial component of total knee arthroplasty for the Korean population. Knee, 14(4):295-300, 2007. 
Liau, J. J.; Cheng, C. K.; Huang, C. H. \& Lo, W. H. The effect of malalignment on stresses in polyethylene component of total knee prostheses--a finite element analysis. Clin. Biomech. (Bristol, Avon), 17(2):140-6, 2002.

Lim, H. C.; Bae, J. H.; Yoon, J. Y.; Kim, S. J.; Kim, J. G. \& Lee, J. M. Gender differences of the morphology of the distal femur and proximal tibia in a Korean population. Knee, 20(1):26-30, 2013.

Lonner, J. H.; Jasko, J. G. \& Thomas, B. S. Anthropomorphic differences between the distal femora of men and women. Clin. Orthop. Relat. Res., 466(11):2724-9, 2008.

Mahfouz, M.; Abdel Fatah, E. E.; Bowers, L. S. \& Scuderi, G. Three-dimensional morphology of the knee reveals ethnic differences. Clin. Orthop. Relat. Res., 470(1):172-85, 2012.

Mensch, J. S. \& Amstutz, H. C. Knee morphology as a guide to knee replacement. Clin. Orthop. Relat. Res., (112):231-41, 1975.

Piriou, P.; Mabit, C.; Bonnevialle, P.; Peronne, E. \& Versier, G. Are genderspecific femoral implants for total knee arthroplasty necessary? $J$. Arthroplasty, 29(4):742-8, 2014.

Stulberg, B. N.; Dombrowski, R. M.; Froimson, M. \& Easley, K. Computed tomography analysis of proximal tibial coverage. Clin. Orthop. Relat. Res., (311):148-56, 1995.

Sun, H.; Luo, C. F.; Shi, H. P.; Yang, G.; Zhong, B.; Zhang, C. Q. \& Zeng, B. F. Morphological measurements of the posterior surface of the normal proximal tibia in a healthy Chinese population. Knee, 21(2):56772, 2014.

Thienpont, E.; Bernardoni, M. \& Goldberg, T. Anthropometric measurements of the femur change with component positioning in total knee arthroplasty. Knee, 23(5):796-800, 2016.

Vaidya, S. V.; Ranawat, C. S.; Aroojis, A. \& Laud, N. S. Anthropometric measurements to design total knee prostheses for the Indian population. J. Arthroplasty, 15(1):79-85, 2000.

Villa, T.; Migliavacca, F.; Gastaldi, D.; Colombo, M. \& Pietrabissa, R. Contact stresses and fatigue life in a knee prosthesis: comparison between in vitro measurements and computational simulations. $J$. Biomech., 37(1):45-53, 2004

Wang, S. W.; Feng, C. H. \& Lu, H. S. A study of Chinese knee joint geometry for prosthesis design. Chin. Med. J. (Engl.)., 105(3):227-33, 1992.

Wevers, H. W.; Simurda, M.; Griffin, M. \& Tarrel, J. Improved fit by asymmetric tibial prosthesis for total knee arthroplasty. Med. Eng. Phys., 16(4):297-300, 1994.
Corresponding author:

Prof. Yusheng Qiu

The First Affliated Hospital of Xi'an Jiaotong University

Xi'an, Shaanxi

CHINA

Email: 1433926191@qq.com

Received: $17-10-2018$

Accepted: 28-01-2019 